\title{
Türkiye'deki İslami Hisse Senedi Endeksinin, Endeks Tabanlı Öznitelikler Kullanılarak Derin Öğrenme Yöntemi ile Tahmini
}

\section{Forecasting of Islamic Stock Index in Turkey with Deep Learning Using Index-Based Features}

\author{
Dilşad Tülgen Çetin ${ }^{1}$ (D), Sedat Metlek ${ }^{2}$ (1)
}

1 (Dr. Öğr. Gör.), Burdur Mehmet Akif Ersoy Üniversitesi, Sosyal Bilimler Meslek Yüksekokulu, Ulaştırma Hizmetleri Bölümü, Burdur, Türkiye

${ }^{2}$ (Dr. Öğr. Üyesi), Burdur Mehmet Akif Ersoy Üniversitesi, Teknik Bilimler Meslek

Yüksekokulu, Elektronik ve Otomasyon Bölümü, Burdur, Türkiye

ORCID: D.T.Ç. 0000-0001-9321-6991; S.M. 0000-0002-0393-9908

\section{Corresponding author:}

Dilșad TÜLGEN CETIN

Burdur Mehmet Akif Ersoy Üniversitesi, Sosyal

Bilimler Meslek Yüksekokulu, Ulaştırma

Hizmetleri Bölümü, Burdur, Türkiye

E-mail address: dtozturk@mehmetakif.edu.tr

Submitted: 28.07 .2021

Revision Requested: 30.11 .2021

Last Revision Received: 03.12 .2021

Accepted: 03.12.2021

Citation: Cetin, D. T. Ve Metlek, S. (2021) Türkiye'deki İslami hisse senedi endeksinin, endeks tabanlı öznitelikler kullanılarak derin öğrenme yöntemi ile tahmini. Acta Infologica, 5(2), 287-298.

https://doi.org/10.26650/acin. 975633
ÖZ

İslami hisse senedi piyasası, yatırımcılara İslam hukukuyla uyumlu hisselere yatırım yapmaları için uygun ortam sağlayan dinamik bir platformdur. Piyasanın gelecekteki fiyat hareketlerini tahmin etmek, yatırımcılar için riski azaltmak ve kârı artırmak gibi önemli avantajlar sağlamaktadır. Yapay zekâ uygulamalarındaki gelişmeler neticesinde derin öğrenme yöntemleri, finansal verilerin tahmininde diğer yöntemlere göre üstün başarı göstermektedir. Finansal zaman serilerinde girdi ve çıktı değişkenleri arasındaki karmaşık iliş̧kiyi başarılı bir şekilde modelleyebilen Uzun Kısa Süreli Bellek (Long Short Term Memory-LSTM) modeli, derin öğrenme yöntemleri arasında dikkat çekmektedir. Bu nedenle çalışmada, Türkiye'de İslami hisse senedi piyasasını temsil eden Katılım endeksinin yüksek doğruluk oranıyla tahmin edilmesi için LSTM modeli tercih edilmiştir. Modelin başarısını doğrudan etkileyebilecek olan özniteliklerin belirlenmesinde, literatürde yaygın olarak kullanılan makroekonomik faktörler veya borsa teknik indikatörleri kullanılmamıştır. Bunun yerine, endeks tabanlı bir yaklaşım izlenerek, BIST 100 (XU100) endeksi, CBOE oynaklık endeksi (VIX), altın oynaklık endeksi (GVZ) ve dolar endeksi (DXY) tahmin modelinin girdi değişkenleri olarak belirlenmiştir. Bu yaklaşım sayesinde birçok parametre, tek bir endeks değeri ile modele dâhil edilmekte ve daha az girdi değișkeni kullanılmaktadır. Böylece bir yandan model basitleştirilirken, diğer yandan modelin tahmin gücü artırılmış olmaktadır. Tasarlanan model ile Katılım endeksi, MAE, RMSE, MAPE ve R2 hata fonksiyonlarında sirasıyla $0,06,0,08,0,02$ ve 0,994 değerleri ile tahmin edilmiştir. Çalışmanın literatüre ana katkısı, Türkiye'de İslami hisse senedi endeksinin tahmininde derin öğrenme yöntemi olarak LSTM modelini kullanan ilk çalıșma olmasıdır. İkincil katkısı ise, İslami hisse senedi endeksinin tahminde endeks tabanlı öznitelikler olan XU100, VIX, DXY ve GVZ parametrelerinin kullanılmasıdır.

Anahtar kelimeler: Derin öğrenme, Uzun kısa süreli bellek, İslami hisse senedi endeksi, Katılım endeksi tahmini

\section{ABSTRACT}

The Islamic stock market is a dynamic platform that provides a suitable environment for investors to invest in shares that comply with Islamic law. Predicting the future price movements of the market provides significant advantages for investors such as reducing risk and increasing profits. As a consequence of developments in artificial intelligence applications, deep learning methods show superior success compared to other methods in predicting financial data. The Long Short Term Memory (LSTM) model, which can successfully model the complex relationship between input and output variables in a financial time series, attracts attention among deep learning methods. For this reason, the LSTM model was used in this study to forecast the Participation index, which represents the Islamic stock market in Turkey, with high accuracy. Macroeconomic factors or stock market technical indicators, which are widely used in the literature, were not used to determine the features that may directly affect the success of the model. Instead, following an index-based approach, the BIST 100 (XU100) index, CBOE volatility index (VIX), the gold volatility index (GVZ), and dollar index (DXY) were determined as the input variables of the forecast model. Thanks to this approach, many parameters are included in the model with a single index value and fewer input variables are used. Thus, the model is simplified and at the same time the predictive power of the model is increased. With the designed model, the Participation index was forecasted with $0.06,0.08,0.02$, and 0.994 values in MAE, RMSE, MAPE, and R2 error functions, respectively. The main contribution of the study to the literature is that it is the first study in Turkey to use the LSTM model as a deep learning method in forecasting the Islamic stock index. The secondary contribution is the use of XU100, VIX, DXY, and GVZ parameters, which are index-based features, in the forecasting of the Islamic stock index. Keywords: Deep learning, Long short term memory, Islamic stock index, Participation index prediction 


\section{GİRIŞ}

İslami hisse senetleri, İslami finansın temel ilkelerine uygun olarak faaliyet gösteren şirketlerin ortaklık paylarını temsil eden hisse senetleridir (Usman, Qamar Jibran, Amir-ud-Din ve Akhter, 2019). Diğer bir deyişle, İslami hisse senetleri;

(i) Faiz, aşırı belirsizlik (garar) ve spekülasyon, kumar ve şans oyunları (maysir) yasaklarına uygun (Çetin, 2021a),

(ii) Alkol, domuz eti, kumar, faize dayalı finansal hizmetler gibi yasaklı alanlar dışında faaliyet gösteren,

(iii) Risk-kâr-zarar paylaşım esasına dayalı şirketlere ait hisse senetleridir (Ibrahim, 2015).

Geleneksel hisse senetleri ile aynı pazarı paylaşmalarına karşın performansları, krizlere karşı gösterdikleri tepkileri ve verimlilikleri açısından farklılıklar gösterirler. İslami finans sisteminin; varlığa dayalı olması, spekülatif kazançlar sağlayan türev ürünlere ve aşırı belirsizlikler içeren işlemlere izin vermemesi, yüksek kaldıraçlı firmaları dışlaması ve kaynakların kullanımında reel ekonomiyi destekleyici tutumu, krizlere karşı daha dayanıklı bir yapı sergilemelerine yol açmıştır (Balcilar, Demirer ve Hammoudeh, 2015; Çetin, 2021b). Bunun yanı sıra, İslami hassasiyetleri olan yatırımcıların fonlarını sermaye piyasasına kazandırmak ve çeşitlendirme sağlayarak riski azaltmak veya kârı artırmak gibi önemli fonksiyonları yerine getiren İslami hisse senedi piyasası, tüm dünyada hızla büyümektedir. 2020 yılsonu itibariyle küresel İslami finansal varlıkların hacmi üç trilyon dolara yaklaşmıştır. Son on yılda ortalama \%7 büyüyen İslami finans sektörünün gelecek dönemlerde büyümesini sürdüreceği öngörülmektedir (IFSB, 2020). Özellikle, Müslüman olmayan gelişmiş ülke piyasalarındaki büyümesi ise dikkate değer bir gelişme olarak değerlendirilmektedir.

İslami finansal araçların, İslami olmaları hususunda uymaları gereken önemli kriterler bulunmaktadır. Söz konusu kriterler, borsalara göre bazı farklılıklar gösterse de temel ilkeleri benzerdir. İslami hisse senetleri, iki önemli incelemeden geçirilir. Bunlar; (i) faaliyet alanlarına göre inceleme ve (ii) finansal oranlarına göre incelemedir. Türkiye'de bir hisse senedinin İslami olabilmesi için şirketin ana faaliyet alanı; faize dayalı finansal hizmetler, alkollü içecek, kumar, şans oyunu, domuz eti, reklam, turizm, tütün mamulleri, vadeli altın, gümüş ve döviz ticareti olmamalıdır. Finansal oranlar açısından ise, faiz getirili nakit ve menkul kıymetlerin veya faizli kredilerin şirketin piyasa değerine oranı \%30'u ve yasaklı faaliyet alanlarından elde edilen gelirin toplam gelire oranı \%5’i geçmemelidir (Katılım, 2021). İslami endeksler ise sektörde kritik bir rol oynamaktadır. Bu endeksler, yatırım yapılabilecek mevcut İslami hisse senetleri evrenini ve İslami yatırımcıların piyasaları ölçme şeklini tanımlamaktadır. Dow Jones (DJ), Financial Times Stock Exchange (FTSE), Morgan Stanley Capital International (MSCI) gibi büyük borsalar İslami hisse senedi endeksleri yayınlamaktadır. Ayrıca, Malezya EMAS İslami endeksi, Pakistan Mezan İslami endeksi ve Türkiye Katılım endeksi gibi ulusal İslami hisse senedi endeksleri bulunmaktadır (Hassan, Aliyu, Saiti ve Abdul Halim, 2020).

Sektörün artan önemi, yatırımcılar açısından İslami endeks tahminini daha önemli hale getirmiştir. Hisse senedi endeksi tahmini, hisse senetlerini ve getirilerini etkileyen çok sayıda sosyal ve ekonomik faktör (örn. makroekonomik faktörler, ekonomik ve politik belirsizlikler vb.) bulunduğundan yatırımcılar ve şirketler için son derece zor, ancak değerlidir. Bu gibi çoklu faktörlerin etkisiyle, hisse senedi endeks verileri çok değişkenli ve doğrusal olmayan bir yapı göstermektedir. Geleneksel borsa endekslerinin tahminine odaklanan birçok çalışma olmasına rağmen, spesifik olarak İslami endeksleri tahmin eden çok az çalışma bulunmaktadır. Literatürdeki boşluğu doldurmak üzere çalışmada, Türkiye'de İslami hisse senedi endeksini temsil eden Katılım endeksinin (KATLM) tahmininde, özellikle zaman serisi verilerindeki başarılarından dolayı, güncel bir makine öğrenme yöntemi olan Uzun Kısa Süreli Bellek (Long Short Term Memory-LSTM) modeli tercih edilmiştir (Sherstinsky, 2020).

Tahmin modelinin girdi değişkenleri belirlenirken, literatürde yaygın olarak tercih edilen teknik indikatörler (Aslam, Mughal, Ali ve Mohmand, 2020; Doaei, Mirzaei ve Rafigh, 2021) veya makroekonomik göstergeler (Narayan, Phan, Sharma ve Westerlund, 2016; Umam, Ratnasari ve Herianingrum, 2019) kullanılmamıştır. Bunun yerine, endeks tabanlı bir yaklaşım izlenerek, XU100 endeksi (XU100), CBOE oynaklık endeksi (VIX), altın endeksi (GVZ) ve dolar endeksi (DXY) tahmin modelinin girdi değişkenleri olarak belirlenmiştir. Endeks tabanlı veriler, tek bir değer ile çok sayıda veriyi temsil etme gücü vermekte ve böylece girdilerin tahmin gücünü artırmaktadır. 
Çalı̧̧ma, Türkiye'de İslami hisse senedi endeksinin (KATLM) tahmininde derin öğrenme yöntemi olarak LSTM modelini kullanan ilk çalışma olması bakımından önem arz etmektedir. Ayrıca, tahmin modelinde girdi değişkenler olarak endeks tabanlı bir yaklaşım izlenmesi, bu çalışmayı benzerlerinden farklı kılmaktadır. Doğru bir tahmin, İslami hisse senedi piyasasında verimsiz yatırımları engellemede ve gelecekteki Katılım endeksi performans trendini belirlemede hayati bir rol oynamaktadır. Bu çalışmanın bulguları, yatırımcıların yatırım ve portföy stratejilerini tasarlamalarına yardımcı olacaktır.

Çalışma beş bölümden oluşmaktadır: İkinci bölümde mevcut literatürdeki ilgili çalışmalara yer verilmekte, üçüncü bölümde analizde kullanılan veri seti ve yöntem açıklanmakta, dördüncü bölümde tasarlanan LSTM sistemi ve bulgular paylaşılmakta ve son bölümde sonuçlar değerlendirilmektedir.

\section{LITERATÜR TARAMASI}

Artan önemi ile birlikte İslami hisse senedi piyasalarına yönelik yapılan akademik çalışmalar son yıllarda artı̧ göstermektedir. Yapılan çalışmalar, çoğunlukla İslami hisse senedi piyasasını geleneksel hisse senedi piyasası ile risk-getiri (Altın ve Caba, 2016; Bayram ve Othman, 2019; Seçme, Aksoy ve Uysal, 2016; Umar, Shahzad, Ferrer ve Jareño, 2018) ve oynaklık (Gandapur, 2020; Haddad, Mezghani ve Al Dohaiman, 2020; Kahyaoğlu ve Akkuş, 2020) açısından karşılaştırmaktadır. Türkiye'deki İslami hisse senedi piyasasını temsil eden Katılım endeksine ilişkin çalışmalar incelendiğinde, mevcut çalışmaların XU100 endeksi ile aralarındaki ilişkiyi araştırmaya ve karşılaştırmaya odaklandığı görülmektedir. Çalışmalara göre; KATLM ile XU100 endeksi arasında kısa dönemli nedensellik ilişkisi bulunmadığı (Bayram ve Othman, 2019) ancak oynaklık yayılımı bulunduğu (Kahyaoğlu ve Akkuş, 2020) ve Katılım endeksinin daha düşük oynaklık ile daha yüksek getiriye sahip olduğu (Altın ve Caba, 2016; Seçme ve diğerleri, 2016) tespit edilmiştir. Bulgular, riski azaltmak veya kârı artırmak amacıyla Katılım endeksinin yatırımcılar açısından portföy çeşitlendirmesinde kullanılabileceği yönündedir (Çetin, 2019). Bununla birlikte, literatürde Katılım endeksinin yapay zekâ yöntemleri ile tahminine ilişkin çalışmaya rastlanmamıştır.

İslami hisse senedi endekslerinin tahminine ilişkin sınırlı sayıda çalışma, Markov zinciri (Yavuz, 2019), çoklu doğrusal regresyon analizi (Mar'i, Pratiwi, Oktanisa ve Utaminingrum, 2019), Otoregresif Koşullu Değişen Varyans (ARCH) modeli (Narayan ve diğerleri, 2016) ve yapay sinir ağları (YSA) (Aslam ve diğerleri, 2020) modellerini kullanmaktadır. Narayan vd., (2016) İslami hisse senedi getirilerinin tahmin edilebilirliğini, Dow Jones İslami endeksinin bileşenleri olan 2577 İslami hisse senedini içeren geniş bir veri seti üzerinde araştırmıştır. Sonuç olarak; en başarılı tahmin edicinin Amerikan hisse senedi getirileri olduğunu, en kârlı bölgenin gelişmekte olan ülkeler ve en kârlı sektörün ise tüketim malları sektörü olduğunu tespit etmişlerdir. Yavuz, (2019), BIST Katılım 30 ve 50 endekslerini, Markov zinciri analizi ile 0,0065 (artışta), 0,0232 (azalışta) ve 0,0297 (sabitte) mutlak hata ile tahmin ederken, Mar'i, Pratiwi, Oktanisa, \& Utaminingrum, (2019) Jakarta İslami endeksini Gauss eliminasyonu, Cramer kuralı ve Gauss-Jordan katsayı belirleme yöntemleriyle sırasıyla, \%0,43, $\% 0,44, \% 0,83$ ortalama mutlak yüzdesel hata (MAPE) değeri ile tahmin etmiştir. Aslam et al., (2020), 25 teknik indikatörü kullanarak, Pakistan KMI-30 İslami hisse senedi endeksini 5,29 MAPE değeri ile tahmin etmişlerdir. Bu tahmin yöntemlerinin yanı sıra, literatürde İslami hisse senedi endeksini LSTM ile tahmin eden az sayıda çalışma bulunmaktadır. Fauzi, (2019), Jakarta İslami endeksini, LSTM modeli ile 0,00019 ortalama karesel hata (MSE) ve 0,014 kök ortalama karesel hata (RMSE) ile tahmin etmiştir. Dami \& Esterabi, (2021), Tahran borsasında işlem gören on hisse senedinin getirilerini, otomatik kodlayıcı (AutoEncoder-AE) ile öznitelik seçimi yaptıkları AE-LSTM modeli ile 0,0343 ortalama mutlak hata (MAE) ile tahmin etmiştir.

Türkiye'de İslami hisse senedi piyasasında Katılım endeksini tahmin etmek amacıyla LSTM derin öğrenme yönteminin kullanıldığı herhangi bir çalışmaya rastlanmamıştır. Bu nedenle, bu çalışmanın sonuçları diğer ülkelerdeki İslami endekslerin (Dami ve Esterabi, 2021; Fauzi, 2019) ve XU100 endeksinin (Kilimci, 2020) LSTM ile tahmin sonuçlarıyla karşılaştırılabilir.

\section{VERİ SETİ VE YÖNTEM}

\subsection{Veri Seti}

Bir yapay zekâ yönteminin başarısı, problemin açık bir şekilde ortaya konulmasına ve girdi değişkenlerle çıktı değişken arasındaki doğrusal olmayan karmaşık ilişkinin uygun şekilde modellenmesine bağlıdır. Özellikle finansal zaman serilerinin 
yapay zekâ ile tahmininde girdi değişkenlerin belirlenmesi, modelin başarısı üzerinde doğrudan etkili olduğundan büyük önem taşımaktadır. Literatürde İslami hisse senedi piyasası ile makroekonomik değişkenler arasındaki ilişkiyi ortaya koyan (Narayan ve diğerleri, 2016; Umam ve diğerleri, 2019) veya teknik indikatörleri (Aslam ve diğerleri, 2020; Doaei ve diğerleri, 2021) tahmin modellerinde girdi değişken olarak kullanan çalışmalar bulunmasına karşın, bu çalışmada farklı bir öznitelik seçimi yöntemi kullanılmıştır. Endeks tabanlı öznitelik seçimi olarak tanımlanabilecek olan bu yöntemde, endeks değerlerinin tek bir değer ile birçok parametreyi temsil etme gücünden yararlanılması amaçlanmaktadır. Tercih edilen yaklaşımın iki önemli avantajı bulunmaktadır:

i. Girdi parametreleri azaltıldığından model basitleştirilmiş ve gereksiz işlem yükünden kaçınılmış olmaktadır.

ii. Tüm parametreler endeks verilerine etki edeceğinden, veri kaybı mümkün olduğunca engellenmiş olmaktadır.

Çalışmada girdi parametreleri olarak kullanılan endeksler, ekonomik teorilerden ve literatürdeki ampirik çalışmalardan yola çıkılarak belirlenmiştir. Girdi değişkenler; (i) XU100, (ii) VIX, (iii) GVZ, (iv) DXY endeksleri ve çıktı değişkeni ise KATLM endeksidir. Çalışmada kullanılan değişkenler Tablo 1'de sunulmaktadır.

Tablo 1

Çalışmada kullanılan değişkenler

\begin{tabular}{lclc}
\hline Kısaltma Kodu & Değişken Adı & \multicolumn{1}{c}{ Veri Türü } \\
\hline KATLM & Katılım 30 Endeksi & Endeks Kapanış Fiyatı & BIST* \\
XU100 & BIST 100 Endeksi & Endeks Kapanış Fiyatı & BIST* \\
VIX & CBOE Oynaklık Endeksi & Endeks Kapanış Fiyatı & Investing** \\
GVZ & Altın Oynaklık Endeksi & Endeks Kapanış Fiyatı & Investing** \\
DXY & Dolar Endeksi & Endeks Kapanış Fiyatı & Investing** \\
\hline
\end{tabular}

*Borsa Istanbul (BIST, 2021).

**Investing (www.investing.com).

Genel olarak, belirlenen değişkenler, hisse senetlerinden beklenen nakit akışlarını ve yatırımcıların beklediği getiri oranını etkilediği için hisse senedi fiyat hareketlerinin öngörüsünde belirleyici olabilir. Belirsizlik göstergelerindeki artışlar, İslami hisse senedi endeksinin düşmesine yol açarken, İslami olmayan endeksteki artışlar İslami hisse senedi endeksinin yükselmesine yol açacaktır. Çalışmada kullanılan girdi değişkenler ile Katılım endeksi arasındaki ilişki aşağıda açıklanmaktadır.

BIST 100 ile Katılım endeksleri (Katılım 30 ve Katılım 50 Endeksleri) arasında güçlü bir ilişkinin varlı̆̆ını ortaya koyan çok sayıda çalışma bulunmaktadır (Güçlü, 2020; İçellioğlu, 2018; Kamışlı ve Esen, 2020). Özellikle, BIST 100 endeksinden Katılım endeksine doğru tek yönlü nedensellik ilişkisinin varlığı, Katılım endeks değerlerinin öngörüsünde BIST 100 endeksinin tahmin belirleyicisi olarak kullanılabileceğine işaret etmektedir.

VIX endeksi, S\&P 500 endeksi alım ve satım opsiyonlarının içsel oynaklık değerleri baz alınarak hesaplanmaktadır. VIX, beklenen borsa oynaklığını ifade etmekte ve yatırımcıların riskten kaçınma derecesini göstermektedir. Bu nedenle, daha yüksek belirsizliğe işaret eden VIX endeksindeki bir artış, hisse senedi getirileri üzerinde olumsuz bir etkiye sahip olacaktır (Gandapur, 2020; Haddad ve diğerleri, 2020; Umar ve diğerleri, 2018).

Altın ve İslami hisse senedi fiyatları arasındaki ilişki iki açıdan önemlidir. Birincisi, altın İslami yatırımcılar açısından güvenli bir yatırım limanı olarak görülmektedir. Bu durumda, Katılım endeksine alternatif bir yatırım aracı olarak değerlendirilebilir. İkincisi ise altın fiyatlarındaki değişimin ekonominin genel durumunun bir göstergesi olarak değerlendirilebilmesidir. Altın fiyatlarındaki artış, hisse senedi piyasasından altın piyasasına doğru fonların çıkışı nedeniyle olumsuz ekonomik koşulların bir göstergesi olabilir (Alkhazali ve Zoubi, 2020). CBOE altın oynaklık endeksi (GVZ), altın fiyat oynaklığının etkisini ölçmek için yaygın olarak kullanılmaktadır (Rahman, Hedström, Uddin ve Kang, 2021; Saka Ilgın, 2019; Trabelsi, 2019).

DXY endeksi, önemli para birimlerinden (Avro, Japon Yeni, İngiliz Sterlini, Kanada Doları, İsveç Kronu ve İsviçre Frankı) oluşan bir sepetin ağırlıklı geometrik ortalamasına karşı Amerikan dolarının değerini yansıtmaktadır. DXY endeksi, hisse senedi piyasası oynaklığının tahmininde önemli bir belirleyici olup (Dai, Zhou ve Dong, 2020), dolar/TL kurunun seyri açısından da son derece kritik bir öneme sahiptir (Ögel ve Fındık, 2020). 
Çalışmada kullanılan XU100, VIX, GVZ, DXY endeks girdi parametreleri ile tahmini hedeflenen KATLM endeksi arasındaki sayısal ilişkiyi ortaya koymak üzere hesaplanan korelasyon katsayıları Tablo 2'de detaylı olarak sunulmaktadır.

Tablo 2

Girdi Parametrelerinin KATLM Endeksiyle Korelasyon İlişkisi

\begin{tabular}{lcccc}
\hline & KATLM & BIST 100 & GVZ & \\
\hline KATLM & 1.0000 & & & \\
BIST 100 & 0.9300 & 1.0000 & 1.0000 & 1.0000 \\
GVZ & -0.0814 & -0.2897 & 0.6270 & -0.0458 \\
VIX & 0.1871 & 0.0282 & -0.3295 & 1.0000 \\
DXY & 0.4033 & 0.5046 & & \\
\hline
\end{tabular}

Veri setinde yer alan değişkenlere ait zaman serisi grafikleri Şekil 1'de sunulmaktadır.
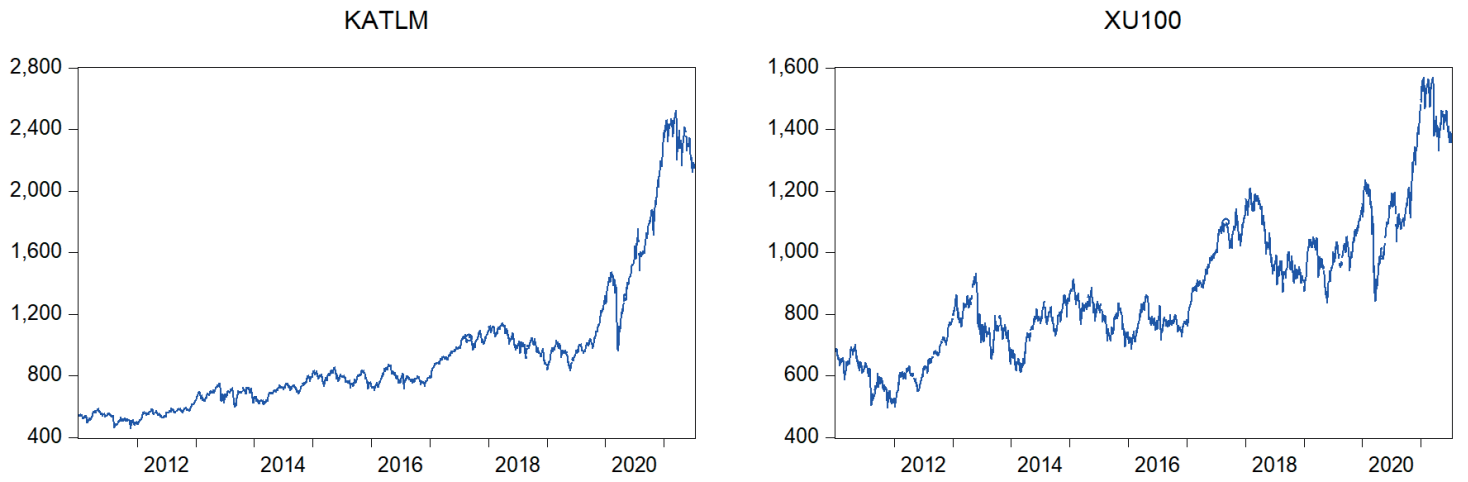

VIX

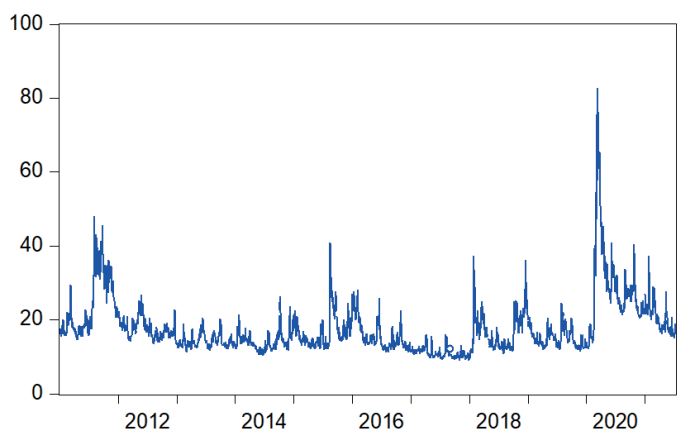

GVZ

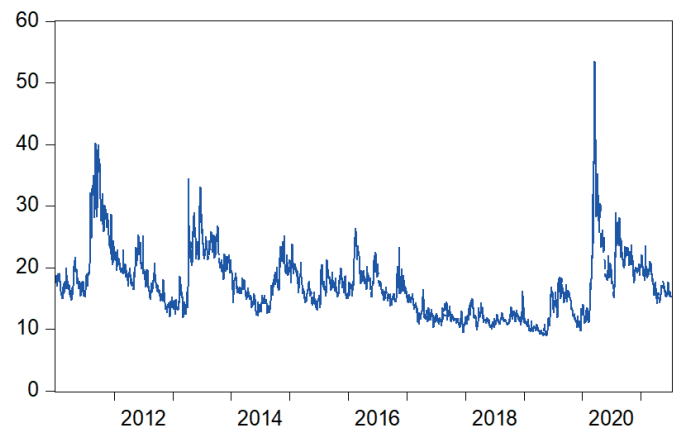

DXY

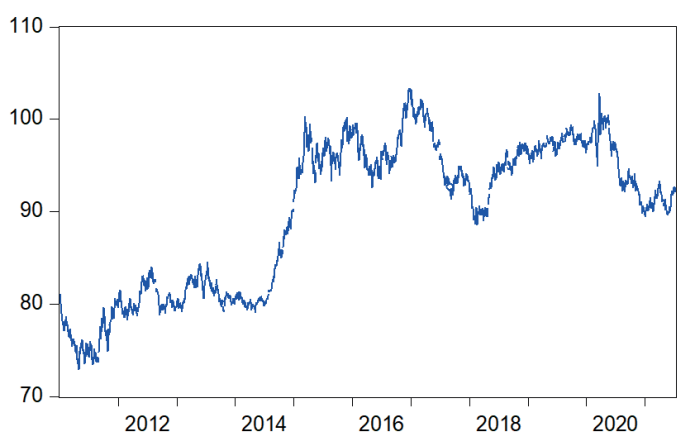

Şekil 1. Değişkenlere ait veri grafikleri 
Şekil l'de, KATLM ile XU100 endeks hareketleri arasındaki benzerlik dikkat çekmektedir. Ayrıca, VIX ve GVZ endekslerinin de aynı yönde hareket eğiliminde olduğu görülmektedir. Buna karşın DXY endeksi her iki grup ile farklı davranış göstermektedir. Çalışmada, bu beş farklı verinin aynı yöntem içerisinde modellenmesi hedeflenmiştir.

Veri dönemi, KATLM endeksinin hesaplanmaya başlandığı tarih olan 07.01.2011 ile verilerin analize alındığı tarih olan 12.07.2021 tarihleri arasında sınırlandırılmıştır. Elde edilen verilerden, eksik olan ve tatil tarihlerindeki farklılıklardan dolayı sağlanamayan veriler, veri setinden çıkarılmış ve sonuç olarak 2645 adet günlük veri elde edilmiştir.

\subsection{Yöntem}

Günümüzde donanım teknolojisinin gelişmesine paralel olarak yazılım sektöründe de önemli gelişmeler meydana gelmiştir. Yazılım sektöründe yaşanan bu önemli gelişmelerden birisi de yapay zekâ algoritmalarında görülmektedir. Yapay zekâ algoritmaları genel olarak donanım bağımlısı algoritmalar olup, doğrusal olmayan verilerde oldukça yüksek başarım oranları sağlamaktadırlar (Metlek, Kayaalp, Basyigit, Genc ve Dogan, 2021). Bu algoritmalar günümüzde, finansal, endüstriyel, askeri ve sağlık alanındaki uygulamalar dâhil çok geniş bir kullanım alanına sahiptir. Yapay zekâ algoritmalarının kullanıldığı alanlardaki sınıflandırma ya da regresyon problemine göre uygun modellerin tercih edilmesi tahmin başarısını artmaktadır (Mengi ve Metlek, 2020; Metlek ve Kayaalp, 2021).

Literatürde birçok finansal analiz uygulamasında ileri beslemeli geri yayılımlı yapay sinir ağı ve türevleri kullanılmaktadır. $\mathrm{Bu}$ algoritmalarda da genellikle Denklem 1 ve 2 de sirasıyla sunulan Sigmoid ve Tanjant Hiperpolik fonksiyonları kullanılmaktadır. Bu fonksiyonların özelliği doğrusal olmayan aktivasyon fonksiyonları olmalarıdır.

$y=\frac{1}{1+e^{-N e t}}$

$y=\frac{e^{N e t}-e^{N e t}}{e^{N e t}+e^{N e t}}$

Denklem 1 ve 2 de kullanılan Net girdi değeri ise $\left(s_{k}^{P}\right)$ Denklem 3 ile hesaplanmaktadır.

$s_{k}^{P}=\sum j^{w_{j k} y_{j}^{P}+\emptyset} k$

Denklem 3'de kullanılan $w_{j k}$ ifadesi k. katmandaki bir elemanın, diğer katmandaki j. elaman ile arasındaki bağlantıyı ifade ederken $\emptyset_{k}$ eşik değerini ifade etmektedir. Yapay zekâ algoritmalarında türevlenebilir aktivasyon fonksiyonları kullanılmaktadır. Bu sayede ağ her ileri geri çalıştığında hata değeri azalarak istenilen sonuca daha da yaklaşması sağlanmaktadır. Genel olarak türevlenebilir aktivasyon fonksiyonu Denklem 4 ile gösterilmektedir ve burada kullanılan $y_{k}^{p} y_{k}^{p}$ değeri, katman elemanın $p$ örneğindeki aktivasyon fonksiyonun çıktısını ifade eder.

$y_{k}^{P}=F\left(s_{k}^{P}\right)$

Matematiksel olarak bu şekilde ifade edilen bir yapay sinir ağı, bünyesindeki aktivasyon fonksiyonları sayesinde doğrusal olmayan regresyonel olayları modellemek için kullanılmaktadır.

Çalı̧̧mada kullanılan veriler, finansal zaman serisi olduğundan regresyonel veriler için kullanılabilen yapay sinir ağ 1 modellerine odaklanılmıştır. Literatürde zaman serilerinde kullanılan modeller incelendiğinde, birçok çalışmada geri dönüşümlü yapay sinir ağı (Recurrent Neural Network, RNN) modelini görmek mümkündür (Chen, Yeo, Lau ve Lee, 2018; Rather, Agarwal ve Sastry, 2015; Saud ve Shakya, 2020). Fakat bu modelin literatürde de belirtildiği üzere gradyan kaybolması veya patlaması sorunları nedeniyle uzun menzilli bağımlılıkları öğrenmesi zordur (Kong ve diğerleri, 2019). RNN'lerdeki bu sorunlarının çözümü için yakın geçmişte LSTM modeli geliştirilmiştir. Gerçekleştirilen çalışmada hem uzun süreli bağımlılıkları modelleyebilmesi hem de zaman serilerinde yüksek tahmin başarısı sağlayabilmesi nedeniyle bu model tercih edilmiştir.

RNN'ler genelde tek katmanlı bir yapıya sahipken, LSTM yapıları ise çok katmanlı yapıya sahiptir. LSTM mimarisinde katmanlar kapı olarak ifade edilmektedir. Bu mimaride temelde giriş, unutma ve çıkış olmak üzere üç adet kapı bulunmaktadır. Bu kapılardan ilki giriş kapısı olup, yeni gelen verilerden hangilerinin saklanacağına karar verir. Bu karar verme işleminde sırasıyla Denklem 5 ve 6'da sunulan sigmoid ve tanh fonksiyonları kullanılmaktadır. 
$i_{t}=\operatorname{sigmoid}\left(W_{i}\left[h_{t-1}, x_{t}\right]+b_{i}\right)$

$C_{t x}=\tanh \left(W_{c}\left[h_{t-1}, x_{t}\right]+b_{c}\right)$

$i_{t}$ ve $C_{t x}$ değerleri kullanılarak bir önceki verilerin bir sonraki hücreye $(C t)$ aktarılması sağlanmaktadır. Bu işlem için Denklem 7 kullanılmaktadır.

$C_{t}=f_{t} * C_{t-1}+C_{t x}$

Denklem 3'te kullanılan ft, LSTM yapısındaki bir diğer kapı olan unutma kapısını ifade etmektedir. Unutma kapısı kendisinden önceki çıkış verisi ile o anki giriş verisi arasında bir değerlendirme yaparak, 0 ile 1 arasında bir değer üretir. Unutma kapsısında gerçekleştirilen işlem Denklem 8'de sunulmuştur.

$f_{t}=\operatorname{sigmoid}\left(W_{f}\left[h_{t-1}, x_{t}\right]+b_{f}\right)$

Elde edilen değerler son olarak LSTM yapısındaki çıkış kapısına gönderilerek hücrenin çıkış değeri üretmesi sağlanmaktadır. Bu işlem için Denklem 9 ve 10 kullanılmaktadır. Hesaplanan hücre çıkış değeri kendisinden sonraki hücreye giriş olarak aktarılmaktadır (Deng ve Yu, 2014).

$o_{t}=\operatorname{sigmoid}\left(W_{o}\left[h_{t-1}, x_{t}\right]+b_{o}\right)$

$h_{t}$

$=o_{t} * \tanh \left(C_{t}\right)$

Denklem 5-10 arasındaki işlemler bir LSTM hücresinde hangi bilgilerin eklenip, hangilerinin çıkarılacağına karar vermektedir.

\section{TASARLANAN SISTEM VE BULGULAR}

Çalışmada, finansal zaman serilerinin tahminindeki başarısından dolayı LSTM yöntemi tercih edilmiştir (Song ve diğerleri, 2020). Modelde, giriş parametresi olarak XU100, GVZ, VIX ve DXY endeksleri, çıkış parametresi olarak KATLM endeksi kullanılmıştır. Toplam 2645 adet günlük veri, K-Fold 5 değerine göre eğitim $(\% 80)$ ve test (\%20) verileri olmak üzere ikiye ayrılmıştır.

Tasarlanan sistem MATLAB ortamında geliştirilmiş olup, 2x Intel Xeon Gold 6130 (32 Core, 2.10GHz, 3.70GHz Turbo, 22MB-İşlemci), 64GB DDR4 (2666MHz ECC-Ram), 256 Bit GDDR5 8 GB (Ekran kartı), X99 Huananzhi Double CPU DDR4 (Anakart) ve 500GB SSD (Harddisk) donanıma sahip bir iş istasyonu üzerinde çalıştırılmıştır. Tasarlanan sistemin genel işleyişi ve mimarisi Şekil 2'de gösterilmektedir.

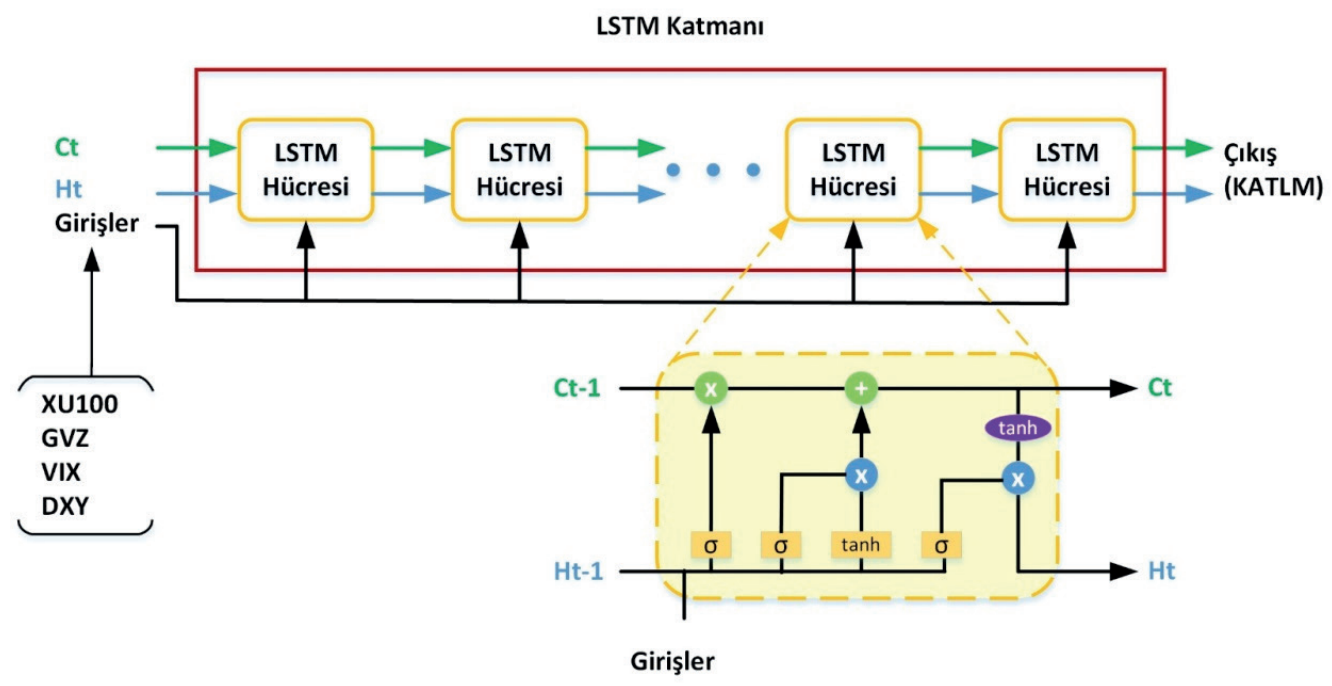

Şekil 2. LSTM mimarisi 
LSTM modelinin içyapısı ile ilgili kullanılan hiper-parametreler, belirlenen aralıklarda test edilmiş ve elde edilen en iyi test değerleri ile birlikte Tablo 3’te detaylı olarak sunulmuştur.

Tablo 3

LSTM modelinde kullanilan parametreler

\begin{tabular}{|c|c|c|c|}
\hline Sira & Hiper-parametreler & Test edilen hiper-parametre aralığı & En iyi test değeri \\
\hline 1 & Initial learning rate & $10^{-4}-0$ & $5 \times 10^{-3}$ \\
\hline 2 & Dropout rate & $0.01-0.9$ & 0.23 \\
\hline 3 & MiniBatchSize & $1-40$ & 25 \\
\hline 4 & GradientThreshold & $0.01-0.99$ & 0.2 \\
\hline 5 & Learn rate drop factor & $0.01-0.9$ & 0.02 \\
\hline 6 & Max epoch iterations & $100-10,000$ & 1100 \\
\hline 7 & LearnRateDropPeriod & $10-1000$ & 500 \\
\hline 8 & NumHiddenUnits: & $10-200$ & 50 \\
\hline
\end{tabular}

Bir yapay zekâ yönteminde kullanılan model kadar, modelin başarısını ölçmek için kullanılan hata fonksiyonları da önemlidir. Tasarlanan LSTM sisteminin tahmin performansını ölçmek için literatürde yaygın olarak kullanılan mutlak hata değeri (MAE), ortalama karekök hata (RMSE), ortalama mutlak yüzdesel hata (MAPE) ve $\mathrm{R}^{2}$ fonksiyonları kullanılmıştır. Kullanılan fonksiyonlar sirasıyla Denklem 10-13 arasında sunulmuştur.

$M A E=\frac{1}{n} \sum_{i=1}^{n}\left|y_{\text {gerçek_i }_{-}}-y_{\text {tahmin__ }_{-}}\right|$

$R M S E=\sqrt{\frac{\sum_{i=1}^{n}\left(y_{\text {gerçek_i } i}-y_{\text {tahmin } \_i}\right)^{2}}{n}}$

$M A P E=\frac{100 \%}{n} \sum_{i=1}^{n} \frac{\left|y_{\text {gerçek_i } i}-y_{\text {tahmin_i }}\right|}{\left|y_{\text {meas_i }}\right|}$

$R^{2}=1-\frac{\sum_{i=1}^{n}\left(y_{\text {gerçek_i }}-y_{\text {tahmin_} \_}\right)^{2}}{\sum_{i=1}^{n}\left(y_{\text {tahmin_ } \_}-y_{\text {gerçek_ort }}\right)^{2}}$

Denklem (11-14)'de kullanılan $y_{\text {gerçek_i }}$, i. gerçek veri değerini, $y_{\text {tahmin } \_ \text {i }}$ i. tahmin değerini, $\underline{y}_{g e r c ̧ e k}$ gerçek verilerin ortalamasını ifade etmektedir. Eğitim ve test verilerinden K-Fold 5'e göre elde edilen hata fonksiyon sonuçları Tablo 4'te sunulmuştur.

Tablo 4

Modelin performans sonuçlarl

\begin{tabular}{|c|c|c|c|c|}
\hline Veriler & MAE & RMSE & МАРЕ & $\mathbf{R}^{2}$ \\
\hline Eğitim & 0.09 & 0.15 & 0.02 & 0.9630 \\
\hline Test & 0.06 & 0.08 & $0 . .02$ & 0.994 \\
\hline
\end{tabular}

Şekil 3’te eğitim ve test verilerinin LSTM modeli ile elde edilen $\mathrm{R}^{2}$ değerlerinin grafikleri sunulmuştur. 

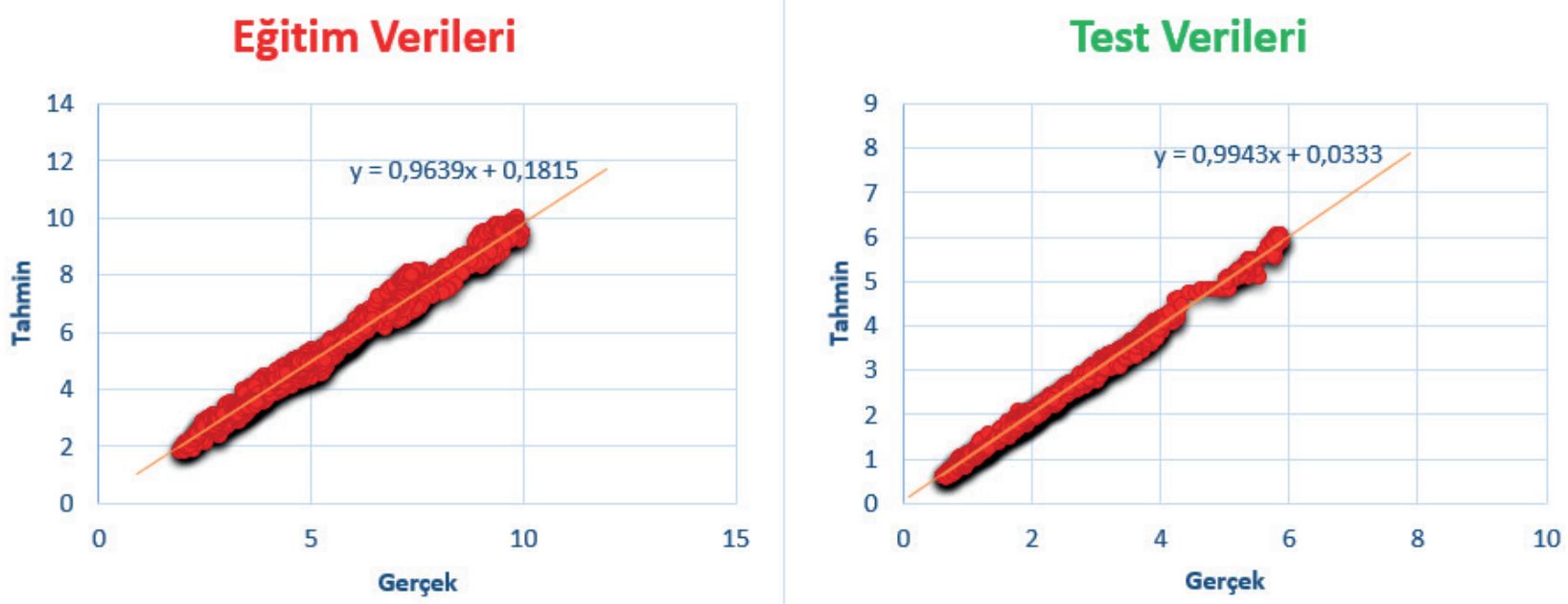

Şekil 3. Eğitim ve test verilerine ait $\mathrm{R}^{2}$ grafikleri

Şekil 3'te yer alan grafiklere ve Tablo 3’te sunulan modelin performans değerlerine göre her iki veri tipi ile modelin üretmiş olduğu değerler \%95'in üzerinde doğruluktadır. Özellikle test verilerinden elde edilen başarım oranı, eğitim verilerine göre daha yüksektir. Bunun da muhtemel nedeni K-fold 5 değerine göre veriler gruplanırken zamansal kırılmaların eğitim setinde daha fazla olmasidır.

Normalize edilmiş eğitim ve test verileri için Tablo 2'de belirlenen en iyi parametre değerleri ile elde edilen KATLM endeksinin tahmin ve gerçek değerlerine ilişkin grafikler, sırasıyla Şekil 4 (a) ve (b)'de sunulmuştur.

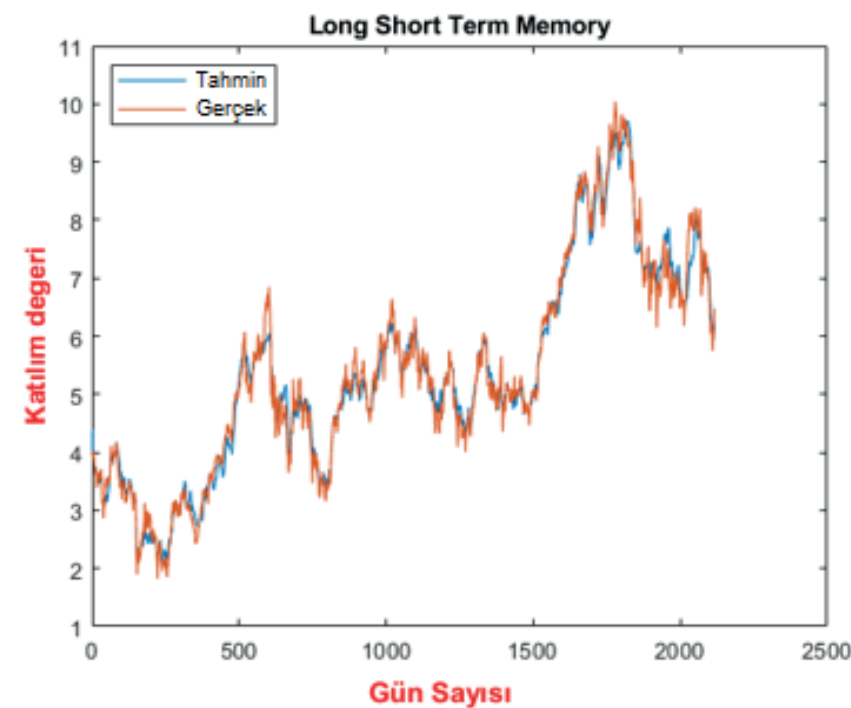

a-) Eğitim verileri

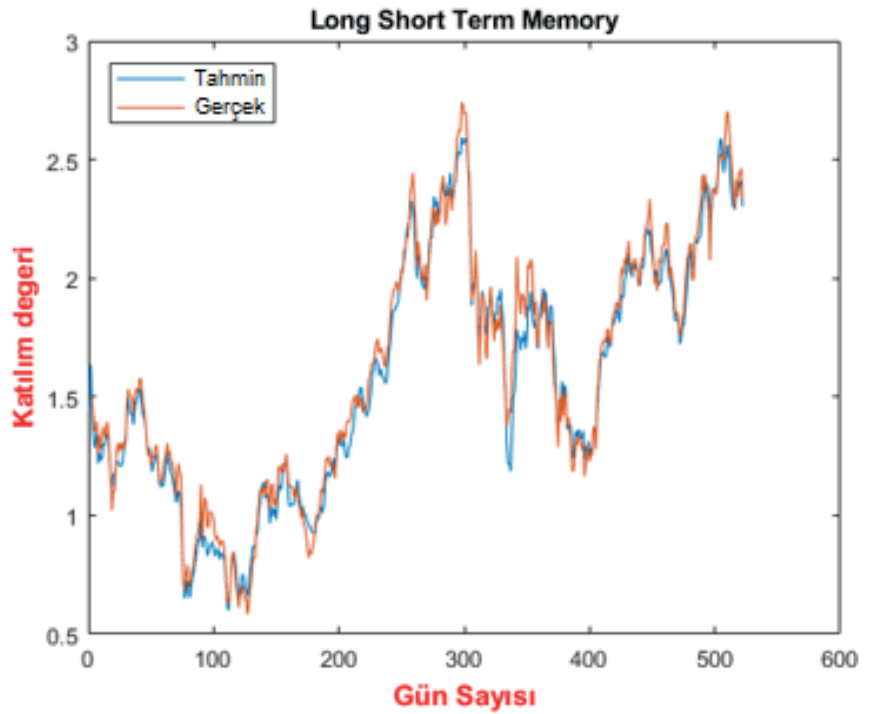

b-) Test verileri

Şekil 4. Eğitim ve test verilerinin sonuçları

Şekil 4'te, KATLM endeksinin gerçek değerlerini temsil eden kırmızı çizgilerle, tasarlanan LSTM sisteminin ürettiği tahmini değerleri temsil eden mavi çizgilerin büyük oranda örtüştüğü, diğer bir deyişle modelin KATLM endeksini yüksek doğrulukta tahmin edebildiği görülmektedir.

\section{SONUÇ VE ÖNERILLER}

Son yıllarda tüm dünyanın odak noktası haline gelen İslami sermaye piyasalarının önemli bileşenlerinden biri de İslami hisse senedi piyasalarıdır. Artan ilgiye rağmen İslami hisse senedi endeksinin tahminine ilişkin çalışmaların son derece az 
olması, bu çalışmanın temel motivasyonunu oluşturmuş̧ur. Çalışmada, Türkiye'deki İslami hisse senedi piyasasını temsil eden KATLM endeksini tahmin etmek üzere en gelişmiş derin öğrenme yöntemlerinden biri olan LSTM modeli kullanılmıştır. Analizde, Ocak 2011-Temmuz 2021 dönemine ait 2645 adet KATLM endeksi günlük kapanış fiyatı kullanılmıştır. Öznitelik seçiminde, ekonomik teoriler ile literatür ışığında endeks tabanlı yaklaşım uygulanmış ve modelin girdi değişkenleri olarak XU100, GVZ, VIX ve DXY endeksleri belirlenmiştir. Veriler, K-fold 5 değerine göre eğitim (\%80) ve test (\%20) verileri olarak ikiye ayrılmıştır.

Tasarlanan model, Tablo 3'te belirtilen hiper-parametre değerleri kullanılarak optimize edilmiş ve sistemin tahmin performansını ölçmek üzere Denklem 7-10 arasında sunulan hata fonksiyonları kullanılmıştır. K-fold 5 değerine göre, test işleminin sonucunda MAE, RMSE, MAPE ve $\mathrm{R}^{2}$ hata fonksiyonlarında sırasıyla 0,06, 0,08, 0,02 ve 0,994 değerleri elde edilmiştir. Ağın yüksek tahmin performansı, girdi değişkenlerin seçimindeki başarısına ve tasarlanan ağ mimarisinin verilere uygunluğuna bağlanabilir.

Çalışma, İslami hisse senedi endeksinin tahmininde LSTM modelinin etkinliğini ortaya koyarak, piyasanın taşıdı̆̆ı belirsizlik ve riskin minimize edilmesine katkı sağlamaktadır. Özellikle ekonomik kriz ortamlarında yapılacak başarılı endeks tahminleri, İslami sermaye piyasası yatırımcılarının risk algısını azaltarak etkin yatııım stratejileri geliştirmelerine ve böylece kârlılıklarını artırmalarına yardımcı olacaktır. Tasarlanan model sayesinde analistler ve portföy yöneticileri piyasanın geleceği hakkında öngörü sahibi olacak, yatırımcılar alım satım kararlarını tahmin sonuçlarına göre verebileceklerdir. Sonuçta daha fazla yatırımcının İslami hisse senedi piyasasında işlem yapması ve piyasanın derinlik kazanması mümkün olacaktır.

Çalışmanın özgünlüğü, LSTM modelinin İslami hisse senedi endeksinin tahmininde etkili bir model olduğunu ve XU100, GVZ, VIX ve DXY endekslerinin tahmin modelinin belirleyicileri olduğunu kanıtlaması açısından önemlidir. Bu makale, Türkiye'de KATLM endeksini LSTM modeli ile tahmin eden ilk çalışma olduğundan, ileride yapılacak çalışmalar için referans teşkil edebilecektir. Tasarlanan LSTM sistemi ve belirlenen hiper-parametreler, diğer ülke borsalarında yer alan İslami hisse senedi endekslerinin tahmininde referans olarak kullanılabilir. Ayrıca, BIST'te yer alan diğer endekslerin tahmininde ve farklı risk faktörlerini temsil eden girdi değişkenleri ile yapılacak analizlerde uygun ağ mimarisi tasarlanarak LSTM modeli kullanılabilir.

Hakem Değerlendirmesi: Dış bağımsız.

Çıkar Çatıșması: Yazarlar çıkar çatıșması etmemișlerdir.

Finansal Destek: Yazarlar finansal destek beyan etmemişlerdir.

Yazar Katkıları: Çalışma Konsepti/Tasarım- D.T.Ç., S.M.; Veri Toplama- D.T.Ç., S.M.; Veri Analizi/Yorumlama- D.T.Ç., S.M.; Yazı Taslağı- D.T.Ç., S.M.; İçeriğin Eleştirel İncelemesi- D.T.Ç., S.M.; Son Onay ve Sorumluluk- D.T.Ç., S.M.

Peer-review: Externally peer-reviewed.

Conflict of Interest: The authors have no conflict of interest to declare.

Grant Support: Authors declared no financial support.

Author Contributions: Conception/Design of Study- D.T.Ç., S.M.; Data Acquisition- D.T.Ç., S.M.; Data Analysis/Interpretation- D.T.Ç., S.M.; Drafting Manuscript- D.T.Ç., S.M.; Critical Revision of Manuscript- D.T.Ç., S.M.; Final Approval and Accountability- D.T.Ç., S.M.

\section{Kaynaklar/References}

Alkhazali, O. M. ve Zoubi, T. A. (2020). Gold and portfolio diversification: A stochastic dominance analysis of the Dow Jones Islamic indices. PacificBasin Finance Journal, 60, 101264.

Altın, H. ve Caba, N. (2016). Borsa İstanbul'da işlem gören katılım endekslerinin performanslarının değerlendirilmesi. Finansal Araştırmalar ve Çalışmalar Dergisi, 8(15), 229-248.

Aslam, F., Mughal, K. S., Ali, A. ve Mohmand, Y. T. (2020). Forecasting Islamic securities index using artificial neural networks: performance evaluation of technical indicators. Journal of Economic and Administrative Sciences, ahead-of-p(ahead-of-print). doi:10.1108/jeas-04-2020-0038

Balcilar, M., Demirer, R. ve Hammoudeh, S. (2015). Global risk exposures and industry diversification with Shariah-compliant equity sectors. Pacific Basin Finance Journal, 35, 499-520. doi: 10.1016/j.pacfin.2015.09.002

Bayram, K. ve Othman, A. H. A. (2019). Islamic versus conventional stock market indicates performance: Empirical evidence from Turkey. Iqtishadia: Jurnal Kajian Ekonomi dan Bisnis Islam, 12(1), 74-86.

Çetin, D. T. (2019). Türkiye'de jeopolitik risk ve İslami hisse senedi endeksi (Katılım 30) arasındaki nedensellik ilişkisi: Ampirik bir analiz. S. Erdoğan, 
A. Gedikli ve D. Ç. Yıldırım (Ed.), ISEFE, International Congress of Islamic Economy, Finance and Ethics içinde (ss. 108-119). İstanbul: Umuttepe Yayınları.

Çetin, D. T. (2021a). İslami finansın temel ilkesi faiz yasağı: Faizin tarihçesi ve ilahi dinlerde faiz. M. Sarıŏlan ve F. Sansar (Ed.), Sosyal ve Beşerî Bilimlerde Araştırma ve Değerlendirmeler içinde (1., ss. 115-142). Lyon, Fransa: Livre De Lyon.

Çetin, D. T. (2021b). İslami finans sisteminde Sukuk (First Edit.). Ankara, Turkey: Gazi Kitabevi.

Chen, W., Yeo, C. K., Lau, C. T. ve Lee, B. S. (2018). Leveraging social media news to predict stock index movement using RNN-boost. Data \& Knowledge Engineering, 118, 14-24.

Dai, Z., Zhou, H. ve Dong, X. (2020). Forecasting stock market volatility: the role of gold and exchange rate. AIMS Mathematics, 5(5), 5094-5105.

Dami, S. ve Esterabi, M. (2021). Predicting stock returns of Tehran exchange using LSTM neural network and feature engineering technique. Multimedia Tools and Applications, 80(13), 19947-19970.

Deng, L. ve Yu, D. (2014). Deep learning: methods and applications. Foundations and trends in signal processing, 7(3-4), 197-387.

Doaei, M., Mirzaei, S. A. ve Rafigh, M. (2021). Hybrid multilayer perceptron neural network with grey wolf optimization for predicting stock market index. Advances in Mathematical Finance and Applications, (In Press).

Fauzi, A. (2019). Forecasting saham syariah dengan menggunakan LSTM. Al-Masraf: Jurnal Lembaga Keuangan dan Perbankan, 4(1), 65-69.

Gandapur, S. K. (2020). Spillover from global volatility index to equity markets of selected Islamic countries. Capital University of Science and Technology, Islamabad, Master of Degree.

Güçlü, F. (2020). İslami ve konvansiyonel hisse senedi piyasaları arasında ortalama ve varyansta nedensellik ilişkisi: ABD, İngiltere, Malezya ve Türkiye Örneği. Gümüşhane Üniversitesi Sosyal Bilimler Enstitüsü Elektronik Dergisi, 11(1), 23-40.

Haddad, H. Ben, Mezghani, I. ve Al Dohaiman, M. (2020). Common shocks, common transmission mechanisms and time-varying connectedness among Dow Jones Islamic stock market indices and global risk factors. Economic Systems, 44(2), 100760.

Hassan, M. K., Aliyu, S., Saiti, B. ve Abdul Halim, Z. (2020). A review of Islamic stock market, growth and real-estate finance literature. International Journal of Emerging Markets, (ahead-of-print). doi:10.1108/IJOEM-11-2019-1001

Ibrahim, M. H. (2015). Issues in Islamic banking and finance: Islamic banks, Shari’ah-compliant investment and sukuk. Pacific Basin Finance Journal, (34), 185-191. doi: 10.1016/j.pacfin.2015.06.002

İçellioğlu, C. Ş. (2018). Sermaye piyasalarında İslami endeksler ve geleneksel endeksler arasındaki ilişkiler: Katılım 30 endeksi ve BİST 100 endeksi. Cumhuriyet Üniversitesi İktisadi ve İdari Bilimler Dergisi, 19(2), 132-144.

IFSB. (2020). Islamic Financial Services Industry Stability Report 2020. Kuala Lumpur, Malaysia: Islamic Financial Services Board. https://www.ifsb. org/sec03.php adresinden erişildi.

Kahyaoğlu, S. B. ve Akkuş, H. T. (2020). Volatility Spillover Between Conventional Stock Index and Participation Index: The Turkish Case. S. Grima, E. Özen ve H. Boz (Ed.), Contemporary Issues in Business Economics and Finance (Contemporary Studies in Economic and Financial Analysis, Vol. 104) içinde (ss. 1-17). Bingley: Emerald Publishing Limited. doi:/10.1108/S1569-375920200000104002

Kamışlı, S. ve Esen, E. (2020). İslami hisse senedi endeksleri arasındaki oynaklık ilişki yapısı. Yönetim ve Ekonomi Araştırmaları Dergisi, 18(1), $108-121$.

Katılım, E. (2021). Katılım Endeksi. 25 Temmuz 2021 tarihinde https://www.katilimendeksi.org/subpage/17/endeks_kurallari adresinden erişildi.

Kilimci, Z. H. (2020). Financial sentiment analysis with Deep Ensemble Models (DEMs) for stock market prediction. Journal of the Faculty of Engineering and Architecture of Gazi University, 35(2), 635-650. doi:10.17341/gazimmfd.501551

Kong, W., Dong, Z. Y., Jia, Y., Hill, D. J., Xu, Y. ve Zhang, Y. (2019). Short-Term Residential Load Forecasting Based on LSTM Recurrent Neural Network. IEEE Transactions on Smart Grid, 10(1), 841-851. doi:10.1109/TSG.2017.2753802

Mar'i, F., Pratiwi, U., Oktanisa, I. ve Utaminingrum, F. (2019). Comparative study of numerical methods in multiple linear regression for stock predictionJakarta Islamic Index (JII). 2019 International Conference on Sustainable Information Engineering and Technology (SIET) içinde (ss. 110-115). IEEE.

Mengi, D. F. ve Metlek, S. (2020). Türkiye'nin Akdeniz Bölgesine ait rüzgâr ekserjisinin çok katmanlı yapay sinir ağ ile modellenmesi. International Journal of Engineering and Innovative Research, 2(2), 102-120.

Metlek, S. ve Kayaalp, K. (2021). Detection of bee diseases with a hybrid deep learning method. Journal of the Faculty of Engineering and Architecture of Gazi University, 36(3), 1715-1732. doi: 10.17341/gazimmfd.749443

Metlek, S., Kayaalp, K., Basyigit, I. B., Genc, A. ve Dogan, H. (2021). The dielectric properties prediction of the vegetation depending on the moisture content using the deep neural network model. International Journal of RF and Microwave Computer-Aided Engineering, 31(1), e22496. doi:10.1002/ mmce. 22496

Narayan, P. K., Phan, D. H. B., Sharma, S. S. ve Westerlund, J. (2016). Are Islamic stock returns predictable? A global perspective. Pacific-Basin Finance Journal, 40, 210-223.

Ögel, S. ve Fındık, M. (2020). Farklı kıtalarda yer alan borsa endekslerinin VIX (korku) endeksi ile ilişkisi. Afyon Kocatepe Üniversitesi İktisadi ve İdari Bilimler Fakültesi Dergisi, 22(1), 127-140.

Rahman, M. L., Hedström, A., Uddin, G. S. ve Kang, S. H. (2021). Quantile relationship between Islamic and non-Islamic equity markets. Pacific-Basin Finance Journal, 68, 101586.

Rather, A. M., Agarwal, A. ve Sastry, V. N. (2015). Recurrent neural network and a hybrid model for prediction of stock returns. Expert Systems with Applications, 42(6), 3234-3241.

Saka Ilgın, K. (2019). Altın ve petrol fiyatları ile volatilite endekslerinin hisse senedi piyasaları üzerindeki etkisi: Gelişmekte olan ülkeler üzerine bir 
inceleme. Erzincan Binali Yıldırım Üniversitesi, Sosyal Bilimler Enstitüsü, Doktora Tezi.

Saud, A. S. ve Shakya, S. (2020). Analysis of look back period for stock price prediction with RNN variants: A case study on banking sector of NEPSE. Procedia Computer Science, 167, 788-798.

Seçme, O., Aksoy, M. ve Uysal, Ö. (2016). Katılım endeksi getiri, performans ve oynaklı̆̆ının karşılaştırmalı analizi. Muhasebe ve Finansman Dergisi, (72), 107-128.

Sherstinsky, A. (2020). Fundamentals of Recurrent Neural Network (RNN) and Long Short-Term Memory (LSTM) network. Physica D: Nonlinear Phenomena, 404, 132306. doi: 10.1016/j.physd.2019.132306

Song, X., Liu, Y., Xue, L., Wang, J., Zhang, J., Wang, J., Cheng, Z. (2020). Time-series well performance prediction based on Long Short-Term Memory (LSTM) neural network model. Journal of Petroleum Science and Engineering, 186, 106682. doi: 10.1016/j.petrol.2019.106682

Trabelsi, N. (2019). Dynamic and frequency connectedness across Islamic stock indexes, bonds, crude oil and gold. International Journal of Islamic and Middle Eastern Finance and Management.

Umam, A. K., Ratnasari, R. T. ve Herianingrum, S. (2019). The effect of macroeconomic variables in predicting Indonesian sharia stock index. JEBIS (Jurnal Ekonomi dan Bisnis Islam) Journal of Islamic Economics and Business, 5(2), 223-240.

Umar, Z., Shahzad, S. J. H., Ferrer, R. ve Jareño, F. (2018). Does Shariah compliance make interest rate sensitivity of Islamic equities lower? An industry level analysis under different market states. Applied Economics, 50(42), 4500-4521.

Usman, M., Qamar Jibran, M. A., Amir-ud-Din, R. ve Akhter, W. (2019). Decoupling hypothesis of Islamic stocks: Evidence from copula CoVaR approach. Borsa Istanbul Review, 19, 56-63. doi: 10.1016/j.bir.2018.09.001

Yavuz, M. (2019). A Markov chain analysis for BIST participation index. Balıkesir Üniversitesi Fen Bilimleri Enstitüsü Dergisi, 21(1), 1-8. 